\title{
Un bateau ivre propio:Pizarnik lectora de Simone de Beauvoir y Virginia Woolf
}

Ludmila Barbero

Instituto de Literatura Hispanoamericana UBA/Conicet.

Fecha de recepción: 12 de abril de 2018. Fecha de aceptación: 1 de noviembre de 2018.

\begin{abstract}
Resumen
La obra de la poeta argentina Alejandra Pizarnik (1936-1972) ha recibido escasas críticas que permitan posicionarla en una relación de diálogo y convergencia con el movimiento feminista. Sin embargo, fue lectora de Simone de Beauvoir, a quien conoció en la década de 1960 en París, y también de Virginia Woolf. Muchos de los interrogantes que aparecen obsesivamente en la escritura de El segundo sexo (1949) se hallan presentes en la obra de Pizarnik, específicamente en sus Diarios, desde las dificultades de una mujer para devenir poeta y rechazar los mandatos familiares, matrimoniales y maternales, hasta cuestiones menos evidentes como la pregunta por la sexualidad infantil. También, Un cuarto propio (Woolf, 2002 [1929]) es un texto que deja huellas en Pizarnik, tanto explícitamente como en la configuración de la espacialidad de su cuarto propio: un espacio valorado ambivalentemente y que, como ocurre con el cuerpo y con el poema en esta autora, será a la vez refugio y prisión.
\end{abstract}

Palabras clave:

Alejandra Pizarnik, Simone de Beauvoir, Virginia Woolf, espacios, infancia.

\begin{abstract}
The work of the Argentinian poet Alejandra Pizarnik (1936-1972) has not been sufficiently connected with the feminist movement. However, she read the works written by Virginia Woolf and by Simone de Beauvoir, whom she met in the 1960s in Paris. Many of the questions that insistently appear in The second sex (1949) are also present in Pizarnik's work, and specifically in her diaries, from the difficulties that a woman has to face to choose poetry over family, matrimonial and maternal commands, to less obvious issues such as child sexuality. Also, the text of A room of one's own (Woolf, 2002 [1929]) is very influential for Pizarnik, both explicitly and implicitly, in the configuration of the "room of her own": a space ambivalently valued, since it is a refuge and a prison at the same time, as it happens with the body and the poem in Pizarnik's writings.
\end{abstract}


La Argentina es el primer país hispanoamericano donde se traduce la obra de Simone de Beauvoir en las décadas de 1950 y 1960, antes incluso que en España. ${ }^{1}$ La circulación de $E l$ segundo sexo ${ }^{2}$ (1949) en este país se da primero en francés y luego, antes de la caída del gobierno peronista, en castellano, a través de las traducciones de Pablo Palant para Psique, distribuida por Siglo XX, en 1954 (Nari, 1999). Entre su publicación (1949) y la década posterior se pueden rastrear la recepción y la circulación de la obra en el campo cultural porteño en retroalimentación con ciertos debates de género que empezaban a cobrar impulso. Muchas feministas reconocen el impacto de la obra beauvoiriana posteriormente, en tanto que las lecturas contemporáneas de las primeras ediciones porteñas parecen haber quedado en la intimidad. Los Diarios (2013) de Pizarnik avalan esta idea: la autora no publicó en vida sino fragmentos de estos escritos situados a mitad de camino entre lo privado y lo público, y aquellos que corresponden a las lecturas de ESS quedaron por décadas en la penumbra. ${ }^{3}$ Con respecto a Un cuarto propio ${ }^{4}$ (2002 [1929]) de Woolf, Pizarnik lee este texto posteriormente al de Beauvoir, en 1959, lo que le permite testimoniar los préstamos y apropiaciones de la autora francesa sobre este libro fundacional.

\section{El feminismo en los Diarios: Pizarnik lectora de de Beauvoir y Woolf}

La recepción de la poética pizarnikiana no ha sido particularmente generosa en lecturas políticas o en clave de género. Su escritura parece configurarse voluntariamente desde un apartamiento con respecto al contexto histórico. Por motivos de espacio, elegimos relevar brevemente el trabajo de dos críticos cuyos aportes en este sentido resultan significativos: Susanne Chávez Silverman y David William Foster.

Chávez Silverman en "Signos de lo femenino en la poesía de Alejandra Pizarnik" (1994), se propone buscar elementos en la obra lírica de la autora en los que se evidencien ciertos posicionamientos genéricos. La crítica parte de la idea de que Pizarnik construye la subjetividad femenina en su poesía a partir de imágenes tendientes a la invisibilidad, la inexistencia, la mudez y la ausencia. Aquí, cabe preguntarnos si la crítica lee estas construcciones del yo como mostración crítica de un conflicto o como retroalimentación de un estado de cosas. Esto es: ¿se trata de evidenciar y generar algún tipo de respuesta sobre el sometimiento femenino? ¿O se lo exhibe involuntaria y sintomáticamente? ¿Se puede propiciar una lectura en la que se rescate su potencial corrosivo más allá de la imposibilidad de constatar cuál es la intención del texto, siempre lejana y elusiva? Creemos que estos son interrogantes clave en una lectura feminista, que Chávez Silverman no se plantea.

En "The look that kills: The unacceptable Beauty of Alejandra Pizarnik's La condesa sangrienta" (1995), Chávez Silverman hace una crítica políticamente situada: se ocupa de analizar el lesbianismo y el enclosetamiento en La condesa sangrienta, siguiendo la línea de Molloy (1999), quien considera LCS como escenificación de un deseo lesbiano, pero también como práctica de silenciamiento. La violencia encarnada por la lesbiana

\footnotetext{
1 Cagnolati, Gentile, Forte Mármol y Vieguer (2008) señalan una fecha tardía e inespecífica de edición en castellano de El segundo sexo (década del 70)..

2 En adelante ESS.

3 Como señala Rocco: "Pizarnik publicó algunos fragmentos de sus Diarios en 1961 y en 1962 en la revista colombiana Mito, y fragmentos de un diario en Poesía = Poesía. Se publicaron póstumamente los fragmentos de sus Diarios incluidos en Semblanza (1984, edición a cargo de Frank Graziano) y los extractos de los Diarios en dos ediciones -2003 y 2013 ampliada-,ambas a cargo de Ana Becciú." (2016: 199).

4 En adelante UCP.
} 
sería directamente proporcional a la represión que conlleva el enclosetamiento del deseo homosexual.

William Foster en "The body in the poetry of Pizarnik" (1994) se propone hacer una lectura política de las representaciones corporales en la poesía de la autora. Analiza, en una serie de poemas, el modo en que se configura un "yo" poético desmembrado y descorporalizado, y correlativamente ciertos agentes antagonistas que, si bien representan entidades inmateriales, son representados a través de imágenes corporales. En "Figuraciones de la corporalidad en Extracción de la piedra de locura" (2015), analizamos cómo el "yo" poético y los antagonistas que aparecen en este poemario en realidad son parte de un todo, configuran una suerte de cinta de Moebius en la que los límites entre el adentro y el afuera se diluyen.

Muchas de las lecturas de Foster son demasiado taxativas y caen en el vicio de la sobreinterpretación. Por ejemplo, para este autor, Pizarnik condena a la figura de Báthory en La condesa sangrienta:

Indeed, it is arguable that she saw the Hungarian noblewoman, as I have already stated, as a figure of the most violent abuse of power and therefore of a whole with those whom she identifies as 'los dueños del silencio' [...] her poetry attempts to countermand. (1994: 338)

No acordamos con esta visión del todo negativa sobre la condesa atribuida a Pizarnik. Pensamos, al contrario, que su fascinación por el personaje eclipsa la condenación moral. De hecho lo que Pizarnik más admira de la nouvelle seudodocumental de Valentine Penrose es que no se detenga en la valoración ética del personaje, sino que se deje llevar por su terrible belleza.

También Foster, en Gay and Lesbian Themes in Latin American Writing (1991), considera que LCS prefigura, debido al abuso de poder de su protagonista, los horrores de la dictadura. Y sentencia a Báthory como duplicación del modelo de la "perversa lesbiana". No acordamos con estas afirmaciones que resultan sesgadas en la medida en que proponen correspondencias uno a uno entre la realidad histórica y la ficción. Pero sí pensamos que, teniendo en cuenta todas las mediaciones que implica trabajar con textos literarios, cabe el intento de situar la obra pizarnikiana en diálogo con problemas que exceden la especularidad del texto.

En sintonía con estas lecturas que posicionan la obra de Pizarnik en un contexto histórico-político, nos proponemos revisar un aspecto muy directo y tangible de la vinculación de la obra de Pizarnik con el feminismo y los debates de género: su lectura de ESS de Simone de Beauvoir, y de UCP de Virginia Woolf, a través de los Diarios, en su edición ampliada de 2013. Para pensar estas lecturas tendremos en cuenta, en primer lugar, las referencias explícitas a estas autoras y, con respecto a la primera, la entrevista que le hace en París (esto será complementado con dos cartas a su entonces psicoanalista León Ostrov). El modo en que Pizarnik construye literaria y autobiográficamente la escena de su encuentro con de Beauvoir parece una puesta en acto de la sentencia beauvoiriana sobre la incapacidad de las mujeres para salir de la inmanencia en el actual (contemporáneo) estado de cosas. En un segundo momento, pensaremos cómo las principales preguntas planteadas por estas pensadoras sobre la posición de las mujeres respecto de la escritura se reiteran obsesivamente a través de los Diarios. Los tópicos escritura versus vida, libertad sexual versus mandato matrimonial, infancia y sexualidad, centrales en la obra beauvoiriana, saturan la narrativa autobiográfica de AP. 
Con respecto al anclaje materialista dado por Woolf a su análisis del tema "las mujeres y la novela", encontramos una afinidad notable con el modo en que Pizarnik escenifica su existencia en los Diarios: se trata siempre de un cuarto, sin importar dónde se encuentre. Y ese cuarto no aparece descripto con grandes variaciones. Esto se torna muy evidente en su estadía en París, porque allí, dejando de lado algunas referencias a la precariedad habitacional y al miedo a convertirse en una clocharde, son escasísimas las alusiones al espacio geográfico, a pesar de que, como veremos más adelante, la escritura pizarnikiana está fuertemente anclada en un imaginario espacial. El "cuarto propio" en AP será, como lo quería Woolf, la condición material de posibilidad de la escritura. Pero también se configurará como lugar de la asfixia, como prisión autoinfligida. Al igual que lo que ocurre con el cuerpo y con la poesía, el cuarto se construye a partir de una valoración inestable, oscilante entre estas dos variables: morada/prisión, y el extenso continuum que las desarticula como polos. Analizaremos también las correspondencias entre la construcción del espacio y las corporalidades en el contexto de los Diarios, porque pensamos que ellas iluminan la inestabilidad de las valoraciones sobre el cuarto: cuerpo y cuarto son lo más propio y lo más ajeno, la condición de posibilidad de la libertad creadora y una prisión de la que no se puede escapar.

Proponemos leer la relación de Pizarnik con ciertos debates del feminismo. En este sentido, pensamos que sus autofiguraciones de niña maldita, o enfant terrible son una forma de resistencia más que un síntoma patológico de cierto descentramiento subjetivo y de cierta incapacidad. Se trata de una niñez queer contestataria. Es posible pensar el posicionamiento poético-político de Pizarnik desde ahí.

\section{De Beauvoir como alusión bibliográfica}

La primera referencia a de Beauvoir en los Diarios es del 5 de julio de 1955:

¡Vivir como Jarry! Aquí me hablaría Mme. de Beauvoir de mi situación de mujer. ¡Desear vivir como Jarry cuando no se puede estar una hora en un café sin que surjan dos gusanos por minuto para perturbar la existencia que esta pobre hembra desea desarrollar! (Pizarnik, 2013: 64)

Esto es, aquí se vuelven explícitos los indicios de una lectura que la hace tomar consciencia sobre esa "condición". Condición se puede leer en dos sentidos: "Índole, naturaleza o propiedad de las cosas/natural, carácter o genio de las personas" versus "estado, situación especial en que se halla alguien o algo". 5

Estos dos sentidos van a ser los que dividan las aguas en lo relativo a las interpretaciones sobre la obra beauvoiriana: ¿describe un estado de cosas o señala fatídicamente una condena que pesa sobre todo el género? Si bien una lectura atenta de la obra nos inclina hacia la primera opción, puede leerse cierto determinismo en la estructuración del discurso. Cuando de Beauvoir hace el recuento de las características de la posición de las mujeres, por momentos parece estar describiendo rasgos intrínsecos de lo femenino ("las mujeres son..."). Hay un deslizamiento entre la descripción de estados de cosas, que es lo que explícitamente se propone hacer, y cierto pesimismo. Una lectura descontextualizada del libro puede caer en una interpretación fatalista (esta interpretación estará presente en AP cuando retome fuera de contexto la sentencia beauvoiriana de que no existe la mujer de genio). 
Un par de semanas después, el 20 de julio, habrá otra referencia a la autora, pero esta vez como ejemplo de resolución de una dualidad: la duplicidad entre su deseo de escribir y el amor heterosexual:

Creo que mi feminidad consiste en no poder "vivir" sin la seguridad de un hombre a mi lado. En los períodos (jactualmente tan escasos!) de ausencia de flirts, me siento terriblemente árida. Inútil. Como si estaría [sic] malgastando mi juventud. Y cuando estoy segura, es decir, cuando camino junto a un hombre que guía mi cuerpo, me siento traidora. Traiciono a ese llamado cercano que me planta junto a la mesita y me ordena: ¡estudia y escribe, Alejandra! Entonces ya no grito " $i m e$ muero de inmanencia!”. ¡No! Entonces, me siento ser. Me siento vibrar ante algo elevado que me asciende junto a sí.

Esta dualidad me rebela. ¿No han de ser compatibles en forma alguna? Buscar ejemplos. ¡Sí! La foto de Daphne du Maurier junto a su aristocrático marido; lord..., tomados amorosamente de la mano. Simone de Beauvoir sonriendo junto a Sartre (no hay que fiarse del periodismo). Katherine Mansfield junto al buen mozo de J. Middleton Murry (pero sus tareas eran análogas y la mayor parte del tiempo estaban separados). Carmen Laforet con sus dos niñas (su mejor novela la escribió en estado de angustia y soledad). ¡Pero también están las otras! ("galeotes dramáticos, galeotes dramáticos”). ¡Qué me dices de las hermanas Brontë, de Clara Silva, de G. Mistral (aridez sublimada), de Colette (en los primeros tiempos), de Mary Webb, de Edna Millay, de Alfonsina Storni, de Safo (¡de Safo!), de C. Espina, de R. Luxemburg y de muchas otras que no conozco! Es irremediable. ¡Es dramático! Una aspira a realizarse. Yo aspiro a realizarme. Cuento para ello con mis dotes literarias. Pero... ¿y si no serían [sic] notables? ¿Si no son más que producto de mi mente confusa y de mi experiencia promiscua? ¿Si no son más que elementos extraídos de mi ser semiarruinado, gastado, que resultan sorprendentes debido a mi edad física? Entonces no solo erré la elección sino que no me realizaré por el camino más natural y sencillo de toda mujer: ¡los hijos! ¡Entonces sería más que frustrada! ¡Sería un ser arrojado para estorbar los pasos productivos de los demás! ¡Ocuparía un espacio inmerecido! Mi vida habría sido en vano. (Ibídem: 80)

El fragmento citado no solo contiene una referencia explícita a de Beauvoir, también incorpora y se apropia de un concepto que ella trabaja en el mismo sentido a lo largo de ESS, cuando señala que mientras dura la labor escritural no se muere de inmanencia:

Ahora nos es posible comprender por qué se encuentran tantos rasgos comunes en las requisitorias dirigidas contra la mujer, desde los griegos hasta nuestros días; su condición ha seguido siendo la misma a través de cambios superficiales, y esa situación es la que define lo que se ha dado en llamar el "carácter" de la mujer: la mujer "se revuelca en la inmanencia", tiene el espíritu de la contradicción, es prudente y mezquina, carece del sentido de la verdad y de la exactitud, no tiene moral, es bajamente utilitaria, embustera, comedianta, interesada... En todas esas afirmaciones hay algo de verdad. Solo que las actitudes que se denuncian no le son dictadas a la mujer por sus hormonas, ni están prefiguradas en los compartimientos de su cerebro: están indicadas por su situación. (Ibídem, 587)

La reflexión beauvoiriana señala la imposibilidad (debida a su situación) de la mujer de dejar de atender a la inminencia de las necesidades cotidianas, prosaicas, materiales referidas a la reproducción de su existencia y de la existencia de los miembros de su entorno, para poder trascenderlos a través del pensamiento y la acción. Pizarnik encuentra la satisfacción de no revolcarse en la inmanencia por medio de la escritura. Pero, como veremos, su escritura versa a menudo sobre cuestiones que podrían leerse como inmanentes, especialmente, por 
motivos lógicos, en sus Diarios. Estos textos liminales, situados entre la vida y la literatura, escenifican la lucha por escapar a ese estado de alienación referido y analizado por de Beauvoir.

Toda esta disyuntiva entre estudio/labor poética y amor en Pizarnik está hablando de la situación de las mujeres con respecto a la escritura y a la independencia o dependencia económica de un marido. Casarse y tener hijos implica relegar la escritura y relegar, de esta manera, el propio deseo. Pero en el amor también se juega una parte importante del deseo. En este no-espacio de la mujer poeta como pareja tiene lugar uno de los mayores conflictos de Pizarnik. Esta imposibilidad es uno de los factores de su permanencia en la infancia, como analizaremos más adelante. La infancia, y la dependencia económica de los padres, se presenta como la única escapatoria para poder ser escritora sin renunciar del todo al amor y al sexo (como enfant terrible). Por eso quizás sea que la infancia en Pizarnik es monstruosa, porque abarca zonas de las que el mundo adulto quiere preservar al niño, y porque se articula más allá del quantum y de la temporalidad de la niñez.

En los Diarios hay vaivenes constantes entre el deseo de escribir y la imposibilidad de producir algo genial, y hay una reiteración del tópico de la frustración literaria, amorosa, profesional. En esta veta autoflagelatoria aparece, en la entrada del 5 de agosto de 1955, Simone de Beauvoir:

Creo que ya no hay nada que defender. Aun con mi ínfima capacidad reflexiva, puedo deducir mi vida. Ha de ser una vida corta en la que no me casaré ni tendré hijos (hasta diría que no tendré relaciones sexuales). Moriré acá en este cuarto, de alguna cosa aparentemente violenta como es algún choque automovilístico o un cáncer de pulmón. Hablé de mis tentativas literarias. Siempre las haré, pero nunca llegarán al acto. No escribiré nunca nada bueno, pues no soy genial. No quiero ser talentosa, ni inteligente ni estudiosa. ¡Quiero ser un genio! ¡Pero no lo soy! Entonces ¿qué? Nada. [...] "Hay mujeres locas y mujeres de talento, pero ninguna tiene esa locura del talento que se llama genio." Simone de Beauvoir. (Ibídem: 126-127)

Dice que no va a casarse ni tener hijos, pero que tampoco va a llegar a algo como escritora. Exhibe su sensación de fracaso literario acompañada por la idea beauvoiriana (de una de Beauvoir leída sesgadamente) de que no existe la mujer de genio. Woolf dice algo muy parecido sobre la inexistencia del genio femenino (que además es genio en masculino, gramaticalmente): "Porque genios como el de Shakespeare no florecen entre los trabajadores, los incultos, los sirvientes" (Woolf, 2008: 37). Pero, al igual que de Beauvoir, no está hablando de algo intrínseco a la naturaleza de las mujeres sino a un estado de cosas históricamente situado.

En la entrada del 29 de febrero de 1958, reaparece la angustia por no poder estar a la altura de la escritura que desea producir. Y en el movimiento de reprenderse por su incapacidad cita a de Beauvoir: "Debo pensar, entonces, que soy una nada? (Simone de Beauvoir y [tachado]: Quieren ser todo y por eso son nada.)"(Pizarnik, 2013: 233).

\section{Woolf en los Diarios}

Pizarnik referencia su lectura de $U C P$ de Virginia Woolf el 8 de marzo de 1959. Lo interesante es que, como la lee cuatro años después de ESS, puede rastrear las apropiaciones beauvoirianas: 
Recién terminé de leer Un cuarto propio de V. Woolf. S. De Beauvoir ha tomado mucho de allí para su Segundo sexo. V. W. es sencillamente adorable. Pero la siento un poco vieja, como del siglo pasado. Estuve pensando sobre las 500 libras al año y el cuarto propio. Yo tengo un cuarto propio, no tengo dificultades económicas apremiantes, gozo de libertad para ir a donde yo quiera. No obstante, soy el ser menos libre. En verdad exagero: la posibilidad de una experiencia rica y vasta está hoy tan vedada como lo estuvo siempre. No me puedo ir al puerto a mirar los barcos por la noche, etc., etc. Pero mi carencia de libertad es debido [sic] a mi no asunción de la realidad. Nada es objeto de mi interpretación ni de mi examen, salvo cuando declaro que no vale la pena. Pero una cosa: basta de reglas éticas. Hay que entrar. (He aquí otra regla ética.) (Ibídem: 275).

Pizarnik dice no ser libre más allá del factor económico, puesto en primer plano en el libro de Woolf como aquello que habilitaría a las mujeres a esgrimir la pluma. Sabemos que Pizarnik sí tuvo apremios económicos: aunque supiera que no iba a quedar en la calle, siempre tenía muy presente su "improductividad" en términos capitalistas y el mandato de ganarse la subsistencia. No obstante, en el fragmento que reprodujimos habla de una incapacidad para asumir la realidad. Si bien no especifica concretamente a qué se está refiriendo con "la realidad", podemos leer esta declaración en sintonía con un leit motiv que recorre toda su diarística, su obra y las apreciaciones que sus allegados y amigos tenían de ella. Sobre este último punto, mencionemos solamente que una de sus mejores amigas, la crítica literaria Ivonne Bordelois, afirma, casi cada vez que se la convoca a hablar de Pizarnik, su incapacidad para manejarse en el ámbito de lo cotidiano. ${ }^{6}$

\section{De Beauvoir como crash romántico-literario}

Como señalábamos, hay dos momentos beauvoirianos en los Diarios: el primero se produce cuando surge la reflexión sobre ESS; y el segundo, cuando Pizarnik la conoce, la entrevista y se enamora de ella. Vamos a pasar entonces al segundo momento:

Ayer me encontré con Simone de Beauvoir. Pero el encuentro no importa tanto como lo que lo precedió: mi miedo. Varias horas de taquicardia, varias horas de pulso enloquecido. Ahora comprendo los terrores de Olga cuando venía lo que ella llamaba la muerte, es esto: una revolución en el corazón. Es el miedo más grande que he sentido. Porque cómo controlar, cómo convencer, si uno es llevado y traído por algo terriblemente malvado. [...]

Simone de Beauvoir me dijo que soy muy tímida. Es cierto: pero lo soy porque lo único que me interesa es agradar, y como no me siento segura de ello, soy tímida. [...]

Y me pregunto cómo haré el artículo sobre S. de B. si está tan enlazado al peor día que viví en mi vida. Cómo Dios mío lo haré. Y es indudable que lo haré. O no tan indudable. (Journal de Châtenay-Malabry, 13 de julio de 1960, 2013: 346-347)

6 Citemos un fragmento de la Biografía escrita por Cristina Piña sobre Alejandra Pizarnik donde releva un testimonio de Bordelois a este respecto: “Alejandra temía los lugares públicos; con frecuencia me pedía que la acompañara a bancos (que consideraba, con razón, monumentos letales y/o funerarios), a tiendas, zapaterías o farmacias. Su no estar en el mundo (o mejor dicho, el que el mundo, como dijo en uno de sus poemas, la hubiera abandonado así) rebotaba en pavores infantiles, paranoicos, enternecedores y tragicómicos" (Piña, 2005: 69). Pensamos, no obstante, que hay un evento en la vida de Pizarnik que pone en jaque la idea de que era una inútil: el 24 de septiembre de 1963 consigna en los Diarios una parte de su gestión para realizarse un aborto. Y esto lo resuelve en el extranjero y absolutamente sola. (Debemos a un diálogo personal con la investigadora Federica Rocco la valoración de estos hechos como desmentida - al menos en cierta medida - de la configuración ya canónica de una imagen romantizada de Pizarnik como infante a perpetuidad.) 
La clave de esa entrevista de la que no han quedado rastros está en la frase: "Pero el encuentro no importa tanto como lo que lo precedió: mi miedo". El encuentro con de Beauvoir activa en Pizarnik una gran frustración y la sensación de que no puede realizar ninguno de sus proyectos de índole práctica. Pero, al mismo tiempo, por la angustia y el miedo que se despliegan, Pizarnik boicotea la entrevista: es como si esta nunca hubiera tenido lugar. De hecho, no hay registros de qué le pregunta, y qué responde la escritora francesa. El relato de esa anécdota no le hace ningún lugar a la entrevistada: se trata más bien de una exhibición del estado mental de la entrevistadora. Lo interesante es cómo este momento es seguido por un estado bastante diferente, y una postura subjetiva en la que ese otro causante de un gran temor se convierte en objeto de amor. ¿Una estrategia de eficacia probada para domesticar aquello que se mostraba perturbador e inaccesible? En la entrada del 16 de julio del mismo año, leemos:

Hoy salí a ver Belleville —siguiendo el consejo de S. de Beauvoir-. Caminé veinte minutos por algunas callecitas, con bastante miedo a causa de los hombres siniestros. Pasé por el Hotel de la Esperanza, que creo que es el que describe Miller. Pero caminando y caminando descubrí que no había salido a ver Belleville sino a Simone de Beauvoir. Y descubrí, horrorizada, que tenía unos deseos angustiosos de verla, de oírla hablar, de mirar sus ojos. Me detuve para insultarme. Solo esto te falta, me dije. Pero me dieron ganas de llorar. Habrase visto semejante idiota, rezongaba la Alejandra juez. Pero la acusada lloraba. Creo que se enamoró de S. de B. Al diablo los desdoblamientos. Creo que me enamoré. El problema persiste. Alguna vez lo tendré que enfrentar. Usted busca a su madre. Sí, indudable, pero si la busco es porque la preciso, la necesito. Y no está bien frustrarme tanto. Por qué diablos no se enamoró ella de mí. Pero aquí está el nudo de la cuestión: debo decirme, por milésima vez, que solo me enamora lo imposible y lo lejano. Que si se hubiera enamorado de mí y me lo hubiera dicho yo, posiblemente, no hubiera respondido nunca a ese amor. Pero esto último es una construcción racional psicoanalítica que no siento. Lo más seguro es que me hubiera enamorado igual. (Pizarnik, 2013: 350-351)

Es posible establecer una comparación con lo que le ocurre con Bataille: Pizarnik se enamora todo el tiempo, pero no de cualquiera. Como señala Cristina Piña en su Biografía:"[En el Café de Flore] podía guiñarse un ojo con Bataille, uno de los fetiches vivientes en los que Alejandra convertía a ciertos escritores muy admirados y con los que inventaba o quizás vivía historias mágicas de una comunicación sutilísima" (Piña, 2005: 103). Recordemos que Bataille es primero una referencia bibliográfica altamente valorada, luego forma parte del pensamiento y el imaginario poético pizarnikiano y, durante su estancia en París, es objeto de una suerte de infatuación. Podríamos hipotetizar que estos enamoramientos operan como respuestas a ese interrogante dualista que surge en sus Diarios a raíz de la necesidad de escapar a la inmanencia a la que la conduce su "posición de mujer". Porque se enamora literariamente de objetos literarios: de esta manera le da una vuelta más a la antinomia literatura-vida, como lo hará también a nivel explícito en muchos de sus escritos publicados en vida, como ocurre con la famosa frase de "El deseo de la palabra" - "Ojalá pudiera vivir solamente en éxtasis, haciendo el cuerpo del poema con mi cuerpo" (Pizarnik, 2014: 270).

El episodio con de Beauvoir también es mentado en dos cartas que Pizarnik escribe a su entonces psicoanalista, León Ostrov, en junio de 1960. En la carta IV, leemos el primer encuentro con la voz de la escritora francesa:

Mi tío Armand -no el que me hospeda, pues tengo 2 tíos aquí-conoce a Simone de Beauvoir y le dijo que yo le puedo hacer un reportaje. Ayer la llamé por teléfono: fue la sorpresa más grande de mi vida: marco el número y me responde una voz de sirvienta gallega: yo creo haberme equivocado y pregunto de nuevo por Mme. de Beauvoir. "C'est elle qui parle" —dice la voz a los gritos. Le murmuré 
mi nombre y le murmuré lo del reportaje. Me respondía a los gritos, una voz tan clara, tan funcional, tan al mismo tiempo generosa - porque se da tanto a pesar de su fealdad- e histérica y flexible. Y hacía tanto contraste con mi lentitud, mi gravedad, mi sentarme sobre cada palabra como si fuera una silla. Cuando corté -el reportaje se hará tal vez la semana próxima - me dio un ataque de risa interminable [...] . No dejé de pensar en esa voz durante todo el día, no sé por qué la asociaba con el abismo que existe entre la poesía y la vida, entre un gran poeta que en general vive como un oficinista y un ser que hace un poema de su vida pero que no puede escribir poemas. (Ostrov, 2012: 41-42)

La funcionalidad de la voz, su carácter o su timbre en el que resuena una eficacia práctica choca a Pizarnik, de un modo semejante a cómo la consterna el encuentro con Marguerite Duras, de quien dirá:

Otra cosa que me dolió fue encontrarme ayer con Marguerite Duras, feliz con sus cuatro baños diarios en el mar, hablándome de sus amigos, de su hijo, de su perro, de comida, de autos sport, y todo comentado sin angustia, sin frases definitivas, sin literatura, como lo hace alguien que pertenece a este mundo y participa plenamente de él. Y yo siempre tan lejana, tan al borde del abismo [...]. (25 de agosto de 1962 - Pizarnik, 2013: 486)

Vemos cómo las autofiguraciones de escritora que Pizarnik construye dejan de lado la eficacia en lo cotidiano. En este punto, podríamos pensar que esa incapacidad de la que habla Bordelois quizás no era tan casual sino que pudo haber respondido a una imagen construida como condición de posibilidad para ser poeta, en el plano de los ideales del yo, entendidos literariamente. La siguiente carta a Ostrov describe el estado de malestar ocasionado por la entrevista:

Pero yo no me he recuperado aún de lo que fue para mí este encuentro: una profunda experiencia del miedo. Y más profunda aun por lo inesperado de este miedo. Comenzó el día del encuentro: despertar y sentir que el corazón me lleva y me trae. Horribles sacudidas. Taquicardia. (Ostrov, 2012: 45). Es una experiencia que aúna lo corporal y lo espiritual en “nupcias horribles. (Ibídem)

A diferencia de otros miedos pasibles de ser volcados en palabras y en versos, este, de acuerdo con la construcción pizarnikiana, se resiste. Según Kristeva, la melancolía es asimbolia, oblitera nuestras capacidades discursivas, las detiene.

En la crónica de Pizarnik, la entrevista no aporta nada nuevo: la interroga sobre la mujer, el arte y cuestiones por el estilo, y de Beauvoir responde con frases similares a las de ESS. La escritora francesa le pregunta cómo piensa dedicarse al periodismo con una timidez tan patológica, le pide que le envíe la nota cuando esté publicada y le recomienda que recorra París (Ostrov, 2012). La clave del encuentro está claramente en la entrevistadora y no en la entrevistada. Y la asimbolia relatada se ve precedida y acompañada en el momento previo al encuentro por un temor a quedarse sin voz:

Imposible todo. Imposible también la lenta agonía - con la mano en el corazónde mi ser paseándose hasta que se hizo la hora y yo entré en Les deux Magots rogando y rogándome que mi voz surgiera — pues mi miedo más profundo (el de los exámenes) — era que la garganta se cerrara. (Ibídem: 45)

Nos detenemos en esta descripción minuciosa de la carnadura corpórea que toma el miedo porque pensamos que es significativo el temor a quedar sin voz ante un personaje cuya vida estuvo consagrada a pensar los espacios de circulación de las voces tradicionalmente acalladas de las mujeres. 


\section{Apropiaciones o convergencias}

\section{Sexualidad infantil - magia - lo monstruoso femenino}

Más allá de las alusiones o citas directas a las obras de de Beauvoir y Woolf en los Diarios y en la Correspondencia, hay afinidades menos evidentes pero también perceptibles entre los temas que obsesionan a estas tres mujeres escritoras.

Tanto Woolf, como posteriormente de Beauvoir, abordan problemáticas de la situación femenina que recorren toda la diarística pizarnikiana: las dificultades de correrse del mandato matrimonial/familiar/maternal y la necesidad de hacerlo para poder desarrollarse como escritora, la necesidad y complejidad para una mujer poeta de ser "productiva" en términos capitalistas, la minorización social de las mujeres, la vara diferencial con que son medidos sus méritos.

Además, en ESS en particular, se analizan tres cuestiones que resultan iluminadoras para pensar la obra de Pizarnik: la infancia y la sexualidad infantil (específicamente en la niña), lo monstruoso y la magia en relación con las mujeres.

En la Cuarta Parte de ESS, titulada "Formación", en los primeros dos capítulos, de Beauvoir habla de la niña y de la joven. Allí despliega los traumas asociados al reconocimiento (mediatizado por lo social) de su corporalidad. La corporalidad femenina es vista como alteridad, y resulta extremadamente sometida al tabú, en especial en la transición a una corporalidad de "mujer" (menstruación, maduración corporal, sexualidad). Desde la juventud, la relación de la mujer con su deseo es de una espera paciente y pasiva: "Aprende que, para ser dichosa, hay que ser amada y, para ser amada, hay que esperar el amor. La mujer es la Bella Durmiente del Bosque, Piel de Asno, Cenicienta, Blanca Nieves, la que recibe y sufre" (de Beauvoir, 2017: 230). La espera como ámbito específico de la joven está muy presente en Pizarnik, en sus Diarios y en sus poemas. Recordemos el "si no vino es porque no vino" de "Extracción de la piedra de locura" (Pizarnik, 2014: 251). En los Diarios resulta recurrente el estado de espera, aunque a menudo no se especifique qué o quién es lx esperadx: "Hay estados que nunca hubiésemos soñado siquiera. El de ahora, por ejemplo. Es un estado de espera vacía. De angustia desprendida. De sutil melancolía árida. Un estado que no sirve para producir o gozar Belleza" (6 de julio de 1955 - Pizarnik, 2013: 65).

También de Beauvoir despliega el tema del cuerpo femenino y las inseguridades que acarrea tanto la anatomía como su valoración social: "No tener confianza en el propio cuerpo es perder confianza en sí mismo. No hay más que ver la importancia que los jóvenes dan a sus músculos para comprender que todo sujeto toma su cuerpo como su expresión objetiva" (2017: 273). Y, a continuación, leemos: "Se ve que si la situación fisiológica de la mujer constituye para ella un handicap es a causa de la perspectiva en que es captada" (ibídem). Esto es, no se trataría tanto de un problema biológico u orgánico de las mujeres sino de una percepción y construcción social. En Pizarnik la obsesión por el cuerpo es omnipresente en los Diarios. Y su deseo no es tener un cuerpo fuerte, sino un cuerpo delgado. El ideal femenino de belleza de su época no es muy distante del que observamos actualmente en cuanto a que se valora la exigüidad de la materia corporal: se trata de cuerpos no capacitados para enfrentar una pelea, ni para ejercer la violencia. Citemos un fragmento para ejemplificar la importancia vital que la imagen corporal tenía para AP: "Descubro que estoy encerrada en mi habitación porque me siento gorda. De lo contrario, hubiera ido a la fiesta de H. P. Pero calculé las calorías de todo el vino que tomaría y decidí quedarme aquí comiendo. Esto es absurdo. Y son solamente tres kilos de más" (31 de octubre de 1959 - Pizarnik, 2013:303). En Pizarnik no hay una mirada crítica sobre el imperativo social de la delgadez. Pero sí hay una visión estética muy particular, muy de "artista surrealista", que procura épater le bourgeois. Citemos brevemente una anécdota contada por Bordelois a Piña y relevada en su Biografía: 
Recuerdo que una vez la acompañé a una farmacia de barrio de Buenos Aires. Debo agregar que una de las consecuencias de ese mutuo no estar Alejandra en el mundo y el mundo en Alejandra era su modo de vestirse, muchas veces inocentemente extravagante. Aquella vez llevaba Alejandra unos pantalones relativamente ceñidos (una curiosidad en la provinciana Buenos Aires de la época, al comienzo de los sesenta), estruendosamente rojos. Naturalmente, no faltaron las miradas inquisitorias. Alejandra movió su rostro celeste y sereno hacia mí y caverneó: “¿Vistequeenestaci-u-dadu-nono-puedeandarco-nanteojos?”. (Piña, 2005: 69)

De Beauvoir estudia en detalle la sexualidad de las niñas: se detiene en la curiosidad infantil, en los juegos, en las conductas de seducción y atracción producidas por la angustia del destete, en cierta precocidad en las niñas por asemejarse a las mujeres adultas, motivadas no por un deseo pero sí por una curiosidad sexual. Indaga ciertas experiencias anteriores y contemporáneas a la maduración sexual en las cuales la mujer, a través de sensaciones que a menudo son de malestar, angustia y pudor, se descubre como un ser sexual. En Pizarnik la infancia siempre aparece sexualizada. De hecho, los poemas y prosas de Pizarnik están plagados de personajes infantiles erotizados, como ocurre con Macho y Futerina: niños-ancianos de Los poseídos entre lilas que se la pasan mentando y practicando actos lúbricos.

Con respecto a los mitos sobre las mujeres, de Beauvoir considera que son maneras de mantenerlas alejadas de lo humano, para evitar verlas como semejantes. "Tal vez el mito de la mujer se extinga algún día: cuanto más se afirman las mujeres como seres humanos, tanto más muere en ellas la maravillosa cualidad de lo Otro. Pero hoy todavía existe en el corazón de todos los hombres" (2017: 142). Pizarnik sabe el modo en que opera esta alteridad absoluta, y esto se ve cuando construye a Báthory despojándola de todo el sustrato mítico que la revestía en la versión de Penrose: crea, en este sentido, un monstruo formidable pero de estatura humana.

Por otro lado, de Beauvoir hablará de una "concepción mágica de la realidad" (2017: 592) en las mujeres. La infantilización a la que el patriarcado condena a la mujer genera una visión mágica de la realidad. En la incapacidad de agencia de la mujer se conforma un imaginario en el cual todo parece producirse sin su intervención. Las cosas aparecen ya hechas:

[...] por mucho que cierre las puertas y tape las ventanas, la mujer no encuentra en su hogar una seguridad absoluta; ese universo masculino, al que respeta desde lejos pero sin osar aventurarse en él, crea un cerco a su alrededor; y precisamente porque es incapaz de captarlo a través de una lógica segura, de unos conocimientos articulados, se siente como el niño o el hombre primitivo: rodeada de peligrosos misterios. Ella proyecta allí su concepción mágica de la realidad, el curso de las cosas le parece fatal y, no obstante, todo puede suceder; distingue mal lo posible de lo imposible, y está dispuesta a creer a no importa quién [...]. (de Beauvoir, 2017: 595)

La construcción sintagmática de La condesa sangrienta tiene una matriz de cuento de hadas. Esta estructura genera la imagen de fenómenos y procesos autogenerados, en los que la agencia humana se diluye y todo parece ocurrir por arte de magia. Recordemos que la agencia humana a la que estamos haciendo referencia es la de una asesina serial. De Beauvoir aporta nueva luz a nuestra lectura, en tanto que pone el eje en las implicaciones de esta "magia" en términos de género. Nos preguntamos entonces: ¿qué efectos tiene a nivel político y genérico el hecho de que el universo femenino se despliegue a través de una narrativa mágica en la que las mujeres parecen no poder intervenir? Pensamos que esta imagen maravillosa del universo femenino transita de la literatura y el arte a las esferas de la praxis vital y ocupa un lugar central 
en las construcciones de género. Al recortarse la posibilidad de agencia de las mujeres se las priva de un posicionamiento subjetivo pleno. La magia aparece entonces como sinónimo de incapacidad para la acción. Lo interesante de la configuración textual de La condesa sangrienta es que la magia no está al servicio de la inacción sino de una agencia perversa en cierto modo diferida (el texto desarrolla una temporalidad especial) y delegada (porque ocurre generalmente con intermediación de sirvientes).

También el concepto de "infancia continua" puede pensarse en Pizarnik, en su resistencia encarnizada a salir de esa etapa. Según de Beauvoir: "La femineidad es una especie de 'infancia continua' que aleja a la mujer del 'tipo ideal de la raza'" (2017: 101). La mujer, en este sentido, es construida como una muñeca viviente:

[...] en la mujer hay un conflicto, al principio, entre su existencia autónoma y su "serotro": se le enseña que, para agradar, hay que tratar de agradar, hay que hacerse objeto, y, por consiguiente, tiene que renunciar a su autonomía. Se la trata como a una muñeca viviente y se le rehúsa la libertad, así se forma un círculo vicioso; porque, cuanto menos ejerza su libertad para comprender, captar y descubrir el mundo que la rodea, menos recursos hallará en sí misma, menos se atreverá a afirmarse como sujeto. (de Beauvoir, 2017: 220)

En cierta medida esto está en Pizarnik, pero contestado. Porque sus construcciones de la femineidad pasiva siempre tienen algo siniestro y revulsivo: ¿el sueño del patriarcado produce monstruos? Podemos decir, siguiendo a Foucault, que las instituciones y las prácticas sociales disciplinadoras a menudo brindan los elementos para efectuar su transgresión. Con las imágenes de la pasividad y muñecas bellas como sueños de piedra, Pizarnik construye a Báthory: una autómata homicida sonámbula que se baña en la sangre de sus víctimas.

En Pizarnik, la infancia siempre está teñida de notas sexuales y perversas. Pensamos que en los Diarios, como también en buena parte de su obra prosística, la clave protofeminista puede leerse en esta construcción anómala de la infancia, en la que resuenan lecturas beauvoirianas pero también batailleanas (aquí hay un cruce interesante en tanto que de Beauvoir cita y abreva de Bataille cuando piensa el erotismo femenino, al margen de que Bataille no pensara a la mujer sino como objeto sacrificial en su concepción del eros). ${ }^{7}$ Creemos que las imágenes de la niña que configura Pizarnik deben ser leídas no como modos de acatar un mandato de género, sino como torsiones que lo interrogan y lo discuten. El campo semántico de la infancia está hipertrofiado en AP. Esto se revela productivo para una lectura feminista, porque la hipertrofia implica la exhibición de un estado de cosas, y porque además el ser-infante en Pizarnik es muy particular. Esta autora construye imágenes de la infancia que tienen un potencial contestatario. No se trata de mujeres-niñas o de mujeres-muñecas en el sentido de la inocencia y pasividad que denuncia de Beauvoir. Se trata de una infancia maldita como bastión contra los mandatos del sistema sexo-género.

7 En Mitos, "Parte tercera" de El segundo sexo de de Beauvoir, leemos: "Y es que el erotismo implica una reivindicación del instante contra el tiempo, del individuo contra la colectividad; afirma la separación contra la comunicación; es rebelde a toda reglamentación" (2017: 192). Vemos entonces cómo, aun sin ser explícita, la lectura batailleana está muy presente en el modo de concebir el erotismo por parte de la pensadora francesa. Recordemos a este respecto que Bataille piensa el erotismo como sacrificio, como consagración del y al instante, como tiempo ajeno a la productividad del universo capitalista, donde el sujeto juega a perder los límites de su individualidad. Es uno de los referentes para pensar la sexualidad y la posición de la mujer en el erotismo para de Beauvoir, a pesar de que en ESS no se detiene a analizar específicamente su obra. 


\section{Un bateau ivre propio}

En cuanto a las apropiaciones de la obra de Woolf, creemos que UCP permite iluminar las construcciones del espacio asociadas al cuerpo que están teniendo lugar en los Diarios. Abundan los significantes que remiten al encierro y, a menudo, a un encierro típicamente femenino (en términos del contexto material de las mujeres): "Rodeada de desechos, de cosas muertas que giran en tu memoria de princesa loca encerrada en tu torre de furia y de silencio" (Pizarnik, 2013: 440). Y también: "Escribí. Fácil es escribirlo. Pero narrar mis atardeceres de prisionera entre las sombras..." (Ibídem: 447). La asfixia se presenta como correlato corporal de la experiencia de ese encierro, que por momentos se muestra como autoinfligido: "¿Quién me busca desde mi mirada? ¿Quién me asfixia desde mis dos manos?” (ibídem: 441).

UCP sirve para pensar el nudo cuerpo-espacio que se produce en los Diarios y cómo el lugar que es un refugio también genera asfixia. Cuerpo-poesía-cuarto son lugares liminales de lo propio-ajeno que se muestran siempre dobles o múltiples en las valoraciones pizarnikianas.

Como señalamos antes, la obra de Pizarnik ha sido, en buena medida, leída como apolítica y sostenida en la reconcentrada intimidad de un yo descentrado. Por esta razón, la pregunta por el espacio puede resultar iluminadora. En los Diarios se pueden percibir ciertas constantes sobre la configuración espacial: el espacio desde el que se habla denota encierro, aislamiento, asfixia, pero por momentos también refugio de un exterior vivido como amenazador.

El espacio puede coincidir con la habitación de la casa familiar que, por lo demás, es la habitación de la infancia, o puede ser una buhardilla en un suburbio de París. Mientras que en la correspondencia Pizarnik/Ostrov hay referencias detalladas al espacio (a la belleza del Sena visto desde un autobús, a una casita en Fontenay-AuxRoses, a la playa con Marguerite Duras, a Capri, al café de Flore, al Deux Magots), en los Diarios las indicaciones geográficas son reducidas, en términos de proporciones textuales. De hecho, entre 1960 y 1964, el período en el que AP vive en París, las referencias geográficas en los Diarios se reducen a: "Este paréntesis tuyo en París ha sido muy bello pero deberías volver a Buenos Aires y “terminar"' (Pizarnik, 2013: 614). Después de practicarse un aborto, hay una entrada situada en "Hôpital de la Cité Universitaire" (ibídem: 623); "El lago del Parc de Montsouris" (ibídem: 571); y escasas referencias más. En cierta medida, de Beauvoir dispara cierta salida del enclaustramiento por parte de Pizarnik, cuando la insta a que recorra la ciudad: como habíamos visto anteriormente, luego de la fatídica entrevista, visita Belleville por consejo de de Beauvoir.

Existe un fuerte anclaje corporal en la configuración de los espacios en Pizarnik, con su correlato en las metáforas espaciales que sobreabundan en las descripciones de la subjetividad y del propio cuerpo. Citemos un fragmento que evidencia cómo AP construye el espacio como cuerpo:

Ausencia vibrante. Galápagos molestos. Sombra del frío que se introduce a través de la cerradura de la ventana. La estufa muda y sonriente halaga mis medias. El humo choca con mis pestañas borroneando la luminosidad ilusoria. Un cruel nihilismo brinca sinuoso en mis espacios. Ruidos. Voces. ¿Y esto es la vida? Extrañeza patológica: la neurosis se clava en mí orgullosa. Mis dedos se quiebran al tratar de desprenderla. Miro los huesos diseminados. Un silencio nebuloso los destaca. Trato de imaginar mi estructura ósea. La ubico en un cajón de la morgue. Náuseas. (28 de julio de 1955 - Pizarnik, 2013: 104) 
Los galápagos son reptiles del orden de los quelonios, parecidos a la tortuga, con membranas interdigitales. ¿A qué se refiere cuando nombra a los galápagos? ¿Son una entidad que se hace presente en la habitación? ¿Es ella en relación con su modo de estar en la habitación? Pensemos que se trata de un animal que lleva la casa a cuestas, que puede estar en el exterior o recluirse en el caparazón en cualquier momento. La posición de estos seres respecto del espacio (exterioridad/interioridad) es siempre liminal. Pero aquí los galápagos generan una incomodidad, son molestos. El frío tiene sombra. Si tiene sombra, necesariamente tiene masa. Tiene cuerpo. La estufa aparece humanizada a la manera de un gato de Cheshire: "La estufa muda y sonriente halaga mis medias". El humo choca con sus pestañas. Y "un cruel nihilismo" es puesto en paralelo con los avatares climático-espaciales que aparecían antes. Esto es, un posicionamiento filosófico se extrapola al ámbito de lo externo-espacial. "Un cruel nihilismo brinca sinuoso en mis espacios". La neurosis también aparece "encarnada": "se clava en mí" y "mis dedos se quiebran al tratar de desprenderla". Las posturas filosóficas y las patologías psíquicas son presencias corporales, en correlato con los objetos materiales que operan como si tuvieran alma.

Asimismo, el cuerpo y el yo son construidos como espacio. En el mismo fragmento que citamos, a continuación del "cruel nihilismo" hacen su aparición "los huesos diseminados" que son sus propios huesos, pero allí están puestos afuera, como otro objeto más de ese espacio que es a un tiempo externo e interno. Además, estos huesos son imaginados como parte de una estructura ósea que el yo ubica en un cajón, podríamos decir para ordenarlos, pero también para situarlos en la esfera de lo mortuorio. Que ciertas entidades inmateriales se materialicen y que lo material tenga un estatuto psicológico o emocional son dos procedimientos que participan de la construcción de un universo onírico en el que toda materialidad se vuelve volátil.

El cuarto en los Diarios aparece, como lo quería Woolf, como el espacio gracias al cual y en el cual la poesía es posible. Con respecto al cuarto como refugio, citemos:

Mi habitación llena de objetos queridos. Adoro entrar y suponer que jamás estuve en ella. Entonces miro con asombro todo y hasta me gusta imaginar que no es mía. Así, renuevo el placer de la posesión a cada instante. Así me obligo a no amarla rutinariamente. Momentos como este, en el que escribo rodeada de un benéfico y raro silencio, son todo lo que requiero para gozar, para amar la vida. Momento de paz, en el que la congoja se aplana, en el que la turbación exterior choca contra los cuadritos de las paredes que la obligan a retirarse, que me llena de felicidad serena y promisoria, tan opuesta a los placeres violentos. ¡Quisiera trabajar así días y días! (Pizarnik, 2013: 78).

El cuarto es la versión miniaturizada de todo aquello que Pizarnik ama en el Universo, en una versión ordenada y limpia. Y es el espacio donde puede entregarse plenamente a su pasión: la lectura y la escritura, la poesía. Pero también, se construye otra imagen de ese espacio, que es el cuarto como prisión o lugar de asfixia: "Madame Angustias sonríe orgullosa de su nuevo vestido. ‘AAdónde vaya habrá sed de correr!' Pero es que hay algo más dramático que esta pobre alma mía en las cuatro paredes, llorando y gimiendo por reproducirse en todo?" (ibídem: 39).

Luego de una ruptura amorosa, en 1954, Pizarnik contrapone explícitamente estas dos valoraciones: el cuarto es el escape a todo aquello que depende de otros y que por ende está fuera del control del yo. Pero, al mismo tiempo, es limitado y asfixiante, porque la obliga a reflejarse infinitamente a sí misma. Las paredes del cuarto se han convertido en espejos. "Quería soñar, fantasear, imaginarme otro escenario que el de mi cama deprimente. No pude" (ibídem: 113). Y: "Hoy 31 de julio, el sol ilumina las cuatro paredes de mi cuarto. Paredes, que son como espejos. En cada uno está 
mi Yo. (Aunque no quiera, he de mirarlo siempre.)" (ibídem: 114). Esa polivalencia del espacio íntimo, a la vez cobijo y prisión, nos hace pensar en Báthory, que es configurada como una suerte de reclusa voluntaria en buena parte de la nouvelle de Pizarnik, y que luego, como castigo por sus crímenes, se convierte en una reclusa por condena judicial. Pizarnik en sus Diarios también se nos presenta a menudo como una emparedada viva.

Si bien no lo desarrollaremos aquí in extenso, pensamos que la construcción corporalizada del espacio y la espacialización del cuerpo en los Diarios resultan clave para entender el funcionamiento refugio-prisión del cuarto. En Pizarnik, parece no haber valoraciones estables o taxativas, sino identificaciones nomádicas: lo intrínsecamente subjetivo es la tierra más ajena. El cuerpo desmembrado es el espacio de lo que realmente se sabe pero también la causa de un dolor incesante (como desarrollamos en el artículo publicado en Rumbos, previamente citado): "Pero no hables de los jardines, no hables de la luna, no hables de la rosa, no hables del mar. Habla de lo que sabes. Habla de lo que vibra en tu médula (...) Habla del dolor incesante de tus huesos" (Pizarnik, 2012: 248).

\section{Infancia queer}

La permanencia en el cuarto se constata, al menos literariamente, en las insistentes referencias a este espacio. Podemos pensar esta permanencia desde el punto de vista de los postulados de Stockton en The Queer Child (2009), quien señala el modo en que el niño queer desarrolla un sidesway growth, o crecimiento hacia los lados, en tanto que el mundo adulto gestiona y propulsa la permanencia del infante en este estadio. Pizarnik crece hacia los lados, se despliega casi desproporcionadamente (en relación con las expectativas sociales que ella misma señala que la sociedad tiene para con una mujer ya adulta como ella) en el ámbito cerrado del cuarto propio en el que se produce una temporalidad diferente de aquella que rige en la esfera de la productividad capitalista. Pizarnik se recluye en un ámbito que tiene sus propias reglas y hasta su propio modo de medir la productividad. El cuarto y las "quinientas libras" están, y por esa razón material es que la libertad creadora es posible. No obstante, resulta insoslayable que el gesto outlaw de rehuirle a la esfera del trabajo se halla en estricta dependencia de la solvencia económica de los padres, tal como ocurre con los niños: pueden dedicarse a jugar, y en esto parecen libres de las ataduras del universo adulto, pero en realidad no tienen una verdadera autonomía, en términos económicos y por consiguiente en términos vitales.

En la escasez de referencias contextuales/geográficas que hay en los Diarios de AP se podría leer el revolcarse en la inmanencia (expresión beauvoiriana a la que, por otro lado, hace referencia Pizarnik directamente). Recordemos lo que dice Woolf sobre el ámbito de expertice de las mujeres en su época: "Por otro lado, toda la formación literaria con que contaba una mujer a principios del siglo diecinueve era práctica en la observación del carácter y el análisis de las emociones" (Woolf, 2008: 49). Pizarnik no sale del ámbito de lo íntimo, de los problemas afectivos y psíquicos que la aquejan, excepto para pensar en literatura. Al mismo tiempo, como decíamos antes, hay un gesto contestatario respecto de los mandatos de género vigentes en su época en la renuncia a ajustarse a un ideal de mujer en el que la producción artística no tiene lugar.

En conclusión, la lectura que Pizarnik realiza sobre ESS de Simone de Beauvoir y $U C P$ de Virginia Woolf tiene proyecciones que exceden las alusiones explícitas en sus Diarios. Con respecto a la primera, el personaje de de Beauvoir permite entender ciertas estrategias literarias de domesticación e incorporación de objetos admirados 
por parte de la autora (recordemos que con Bataille el proceso de incorporación del autor admirado a la esfera vital era similar al caso de Beauvoir). También algunas preguntas obsesivas de ESS rondan la escritura pizarnikiana: la sexualidad infantil, el matrimonio como medio de sujeción y a la vez salida fácil para obtener el bienestar económico, las dificultades de empuñar la pluma, la construcción de una imagen mágica del posicionamiento femenino respecto de la acción, los mitos femeninos como medio para des-humanizar a las mujeres. Con respecto a la lectura de Virginia Woolf, hemos visto que tampoco se agota en las referencias explícitas, sino que también ilumina desde un costado materialista la construcción de la espacialidad privilegiada de los Diarios: en ellos las escenas transcurren en el mismo lugar, que es a la vez la habitación infantil y el estudio donde la poeta ejerce su oficio. Este lugar es representado a menudo con imágenes corporales, así como el cuerpo aparece vislumbrado como una entidad espacial. El espacio, como a menudo ocurre también con el cuerpo en la poesía de Pizarnik, será condición de posibilidad de la escritura y, como tal, refugio donde todo parece estar bajo control, pero también por momentos se convertirá en una prisión.

La infante maldita se empareda viva en su barco ebrio, cuarto familiar, buhardilla de la bohemia parisina, para abocarse a la poesía, escapando a los mandatos matrimoniales/ maternales, para atentar contra el aforismo que retoma de Simone de Beauvoir para flagelarse: "No existe la mujer de genio". Y su obra entera es una gran desmentida a esa afirmación. 


\section{Dibliografía}

》 Barbero, L. (2017). Las poupées de Alejandra Pizarnik. En Lejana. Revista Crítica de Narrativa Breve [S.I.], núm. 10, pp. 158-172, noviembre. En línea: http://ojs. elte.hu/index.php/lejana/article/view/170 (Consulta: 24/11/2017. URL: https:// doi.org/10.24029/lejana.2017.10.170

"------ (2018). "Belle comme un rêve de Pierre: La Condesa Sangrienta de Alejandra Pizarnik como reescritura de cuentos de hadas. En Anclajes. Santa Rosa, Facultad de Ciencias Humanas, Universidad Nacional de La Pampa.

"Barbero, L. y Pampín, A. (2015). Figuraciones de la corporalidad en Extracción de la piedra de locura. En Orillas, Rivista d'ispanistica núm. 4, Dossier Rumbos. Universidad de Padua.

»Beauvoir, S. de (2017 [1949]). El segundo sexo. Buenos Aires, De Bolsillo.

》 ------- (XXXX). Mitos. FALTA Es la „Parte tercera“ de El segundo sexo.

"Cagnolati, B.; Gentile, A. M.; Forte Mármol, A. y Vieguer, F. (2008)- De la Argentina al mundo hispanoamericano: las traducciones con acento porteño de la obra de Simone de Beauvoir. Presentado en Jornada de homenaje a Simone de Beauvoir en el cincuentenario de El segundo sexo, organizada por el IIEGE.

"Chávez Silverman, S. (1994). Signos de lo femenino en la poesía de Alejandra Pizarnik. En Azar, I. (ed.). El puente de las palabras: homenaje a David Lagmanovich. Washington D.C. Organization of American States.

»------ (1995). The Look That Kills: The Unacceptable Beauty of Alejandra Pizarnik's La Condesa Sangrienta. En Bergmann E. y Smith, P. J. (eds.). ¿Entiendes? Queer Readings, Hispanic Writings. Durham, Duke University Press Books.

"Foster, D. W. (1991). Gay and Lesbian Themes in Latin American Writing. Austin, University of Texas Press.

》------- (1994). The Representation of the Body in the Poetry of Alejandra Pizarnik. En Hispanic Review, vol. 62, núm. 3.

》Molloy, S. (1999). De Safo Baffo: diversiones de lo sexual en Alejandra Pizarnik. En Estudios. Revista de investigaciones literarias y culturales. núm. especial: Cuerpo, sexualidad, género, año 7, enero-junio, núm. 13.

»Nari, M. M. A. (2002 [1999]). No se nace feminista, se llega a serlo. Lecturas y recuerdos de Simone de Beauvoir en Argentina, 1950 y 1990. En Mora, 8.

» Piña, C. (2005). Alejandra Pizarnik: una biografía. Buenos Aires, Corregidor.

»Pizarnik, A. (1984). Semblanza. Graziano, F. (ed.). México, FCE.

» ------- (2013). Diarios. Becciú, A. (ed. ampliada). Barcelona, Lumen.

»----- (2014a). Poesía completa. Buenos Aires, Lumen.

》------- (2014b). Prosa completa. Buenos Aires, Lumen.

»Ostrov, A. (2012). Alejandra Pizarnik/León Ostrov. Cartas. Villa María, Editorial Universitaria de Villa María.

》 Rocco, F. (2016). Los diarios de Alejandra Pizarnik: El loco afán por reescribir(se). En Diarios latinoamericanos del siglo XX. Bruselas, Éditions scientifiques internationales. 
"Stockton, K. (2009). The Queer Child. Londres, Duke University Press.

»Woolf, V. (2008 [1929]). Un cuarto propio. Barcelona, Seix Barral. 